Ciência e Natura, Santa Maria v.38 Ed. Especial-

IX Workshop Brasileiro de Micrometeorologia, 2016, p. 442 - 446

Revista do Centro de Ciências Naturais e Exatas - UFSM

ISSN impressa: 0100-8307 ISSN on-line: 2179-460X

\title{
Low frequency modulation of atmospheric surface layer in Amazonia
}

Modulação da camada limite superficial na Amazônia por movimentos de baixa frequência

\section{Celso von Randow ${ }^{1}$, Francisco Miranda ${ }^{2}$ e Leonardo Deanne de Abreu Sá ${ }^{3}$}

\author{
${ }^{1}$ Centro de Ciência do Sistema Terrestre, INPE, São José dos Campos, SP \\ celso.vonrandow@inpe.br \\ ${ }^{2}$ Centro de Estudos Superiores de Parintins, Universidade do Estado do Amazonas, Parintins, AM \\ f_miranda31@hotmail.com \\ ${ }^{3}$ Centro Regional da Amazônia, INPE, Belém, PA \\ leodeane@uol.com.br
}

\begin{abstract}
We investigate possible effects of modulation of the surface layer over Amazonian forest by motions that occur at time scales longer than the usual turbulent time scales (referred to as "low-frequency motions"). We present empirical evidence of their occurrence, possible influences on the turbulence structure in the surface layer and its effects on deviations of Monin-Obukhov Similarity theory predictions. To parameterize these effects, we estimate an 'outer layer' 'fluctuating' friction velocity ( $v$ *) as proposed by McNaughton (2006) to represent the additional energy transported down from the variable motions of the outer layer to the surface layer and study how frequently they could be significantly affecting the structure of surface layer. Based on analyses of scale variability of variances and covariances and relations with the parameterized $v^{*}$, we propose that the relation between $v^{*}$ and $u^{*}$ could be used as an indicator of the strength of low frequency modulations in the region. We found that the ratio $v^{*} / u^{*}$ is above 2 for roughly $50 \%$ of the unstable runs analyzed and it is likely that in these cases the surface layer is different from the textbook descriptions
\end{abstract}

Keywords: Low-frequency motions, surface layer, Amazonia, Monin-Obukhov Similarity.

\section{Resumo}

Investigamos possíveis efeitos de modulação da camada superficial sobre a floresta Amazônica por movimentos que ocorrem em escalas de tempo mais longas do que as escalas de tempo turbulentas usuais (referidos aqui como "movimentos de baixa-frequência"). São apresentadas evidências empíricas de sua ocorrência, possível influência na estrutura da turbulência na camada superficial e seus efeitos induzindo desvios nas relações da teoria da similaridade de Monin-Obukhov. Para parametrizar estes efeitos, estimamos uma escala de velocidade de fricção "flutuante" $\left(v^{*}\right)$ proposta por McNaughton (2006), para representar o transporte adicional de momento pela variabilidade da camada externa ('outer layer') transferido para a camada superficial, e estudamos o quão frequente estes movimentos podem afetar significativamente a estrutura da camada superficial. Baseando-nos em análises da variabilidade por escala das variâncias e covariâncias e relações com v*, propomos que a relação entre $v^{*} e u^{*}$ pode ser usada como um indicador da importância das modulações de baixa-frequência na região. Os resultados mostram que a razão $v^{*} / u^{*}$ é maior que 2 para aproximadamente $50 \%$ dos dados em condições instáveis analisados, e é provável que, nestes casos, a camada superficial é diferente das descrições clássicas. 


\section{Introduction}

The atmospheric boundary layer over Amazonian forest frequently contains slowly moving large eddies caused by strong convective motions and/or local circulations induced by the heterogeneity of the surface. These motions occur at time scales longer than the usual turbulent time scales and are here referred to as low-frequency motions. Unfortunately, it is still difficult to quantify their effects on the turbulent exchange processes in the surface layer.

Almost all theoretical and experimental studies of atmospheric turbulence rely on the separation between larger scale phenomena and turbulent motions by the spectral gap. In practice, the spectral gap provides a means of defining a cut-off timescale to separate the mean (background) motions, which are treated deterministically, and turbulent fluctuations, which are treated statistically. Often, however, there is no spectral gap, as for example, with larger cumulus clouds acting like large eddies with time scales on the order of an hour. These might enhance the spectrum around these scales, spoiling a clear scale separation and making it a difficult regime to properly describe (Stull, 1988).

In some cases, especially those characterized by poor turbulent mixing of the atmosphere, there are indications that the low-frequency variations contribute up to $30 \%$ of the total covariance in Amazonian forests (Von Randow et al., 2002; Finnigan et al., 2003). However, it is not always clear to what extent these variations represent actual transport that should be accounted for to evaluate the total exchange in budget studies, or non-stationarities in the signals that should be disregarded in the flux calculations.

The complications related to the influence of low-frequency motions revolve around whether these variations in long timescales are "locally meaningful" or represent features of the wider landscape that are not related to the local surface (Malhi et al., 2004). When there is no clear spectral gap defining a separation between turbulent and larger-scale processes, the choice of the cut-off averaging timescale to define mean and turbulent fluctuation parts of turbulent variables may become arbitrary. On one hand, the cut-off timescale should include all scales that carry a significant amount of mass and energy flux. On the other hand, the basis of nearly all models of surface-atmosphere interactions relates the fluxes to the local mean wind shear and temperature stratification. Ideally, these models should include the effects of low-frequency modulation (by larger-scale motions); however, this is still at very premature stages. Better understanding of how the lowfrequency motions affect the structure and scales of turbulent processes is therefore crucial for the reduction of uncertainties of flux estimates and for the improvement of future models of turbulent transport.

In most applications in the surface layer, relying on the Monin-Obukhov similarity theory (MOS), the characteristics and structure of turbulence are described by 'local' parameters parameters of the surface layer itself, such as friction velocity, surface heat flux and buoyancy - but there is evidence that some properties are also influenced by 'outer' parameters parameters of the mixed layer, for example, such as the height of the boundary layer and the convective velocity scale (e.g. Hogstrom, 1990; McNaughton and Brunet, 2002).

In a new view of the formation of eddies in the surface layer, McNaughton (2004, 2006) proposes a new model of turbulence structure, in which the active turbulence in the surface layer forms a self-organizing system that resists change by local instability. According to McNaughton theory, the outer convective motions (larger boundary-layer eddies) modulate the surface layer structure, enhancing the dissipation rate of TKE ( $\square$ ).

Based on this model, McNaughton (2006) analyzed the terms of the kinetic energy budget equation and argued that the dissipation rate of TKE could be used to parameterize a fluctuating friction velocity $v^{*}$, that represents the additional energy transported down from the lowfrequency motions of the outer layer to the surface layer. An appropriate velocity scale to be used in the surface layer is then a dissipation 
velocity', $u_{\varepsilon}=(k z \varepsilon)^{1 / 3}=\left(u^{* 3}+\overline{v^{* 3}}\right)^{1 / 3}$, and not $u^{*}$ only, as in MOS theory.

Using the dissipation velocity scale to parameterize the effects of outer-layer modulation on the surface layer, we estimate how frequently the low-frequency motions influence the turbulence structure near the surface over Amazonian forest.

\section{Empirical evidence of low frequency modulation}

To give an example of the variable contribution of processes occurring on different scales to the surface layer fluxes, we generated in figure 1, estimates of scale contributions to latent heat fluxes, measured at the $53 \mathrm{~m}$ above the ground, over the ZF-2/LBA flux tower in Manaus, AM (also known as 'K34 tower'). The data plotted in this figure were generated using multi-resolution decomposition, a type of wavelet transform (see e.g. Howell and Mahrt, 1997), which projects the turbulent signals into frequency (and spatial) scale classes, and provides the contribution of motions of different scales to the "total" variances and covariances.

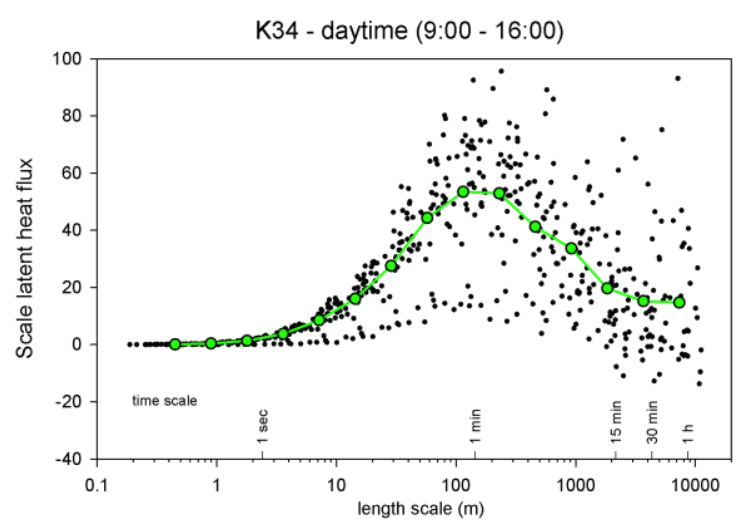

Figure 1: Contribution of motions at different scales to the latent heat flux over Manaus ZF-2 forest ('K34 tower'). The thick line represents binned averages and the dots are individual records.

The figure presents on the x-axes both the temporal scales and the spatial scales of motions, where the latter are estimated using the average wind velocities and the assumption of Taylor's hypothesis, and on the y-axes the contribution of motions at a particular scale to the heat flux. It is noted that, on average (highlight in green line), most of the flux occur through processes of less than $15 \mathrm{~min}$, but there is a significant contributions to the fluxes on scales on the order of 1 hour in individual samples. Note also that these longer timescale processes ('larger eddies') many times contribute to fluxes in opposite sign (negative fluxes in this example).

The sources of low-frequency contributions to the total exchange and the interactions between the large eddies and the surface layer are not yet well understood. They are, however, frequently proposed as the cause for the lack of energy balance closure at many sites (Twine et al., 2000; Finnigan et al., 2003; von Randow et al., 2004). Moreover, they are likely to explain part of the scatter around the expected trend lines of similarity relationships, such as the relationships between the standard deviations of scalar signals and the stability parameter $\zeta$.
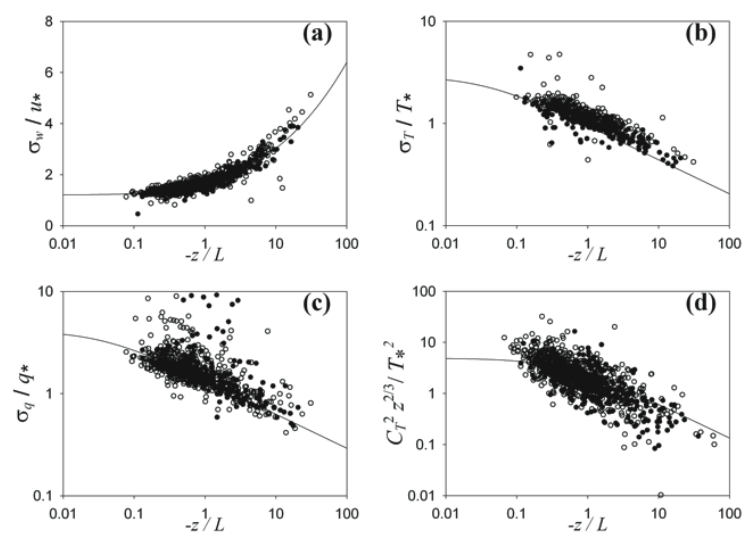

Figure 2: Standard deviations of (a) vertical velocity $w$, (b) air temperature $T$ and (c) humidity $q$, and (d) the structure parameter of temperature $C_{T^{2}}$, measured over Amazonian forest at the K34 site, scaled by the conventional scaling parameters, as a function of $-\zeta$. The solid lines represent the empirical curves proposed by MOS.

Further analyzing the scale variability and low-frequency motions in this site, Von Randow et al. (2006) found that in scales larger than a few hundred meters, the vertical wind variations tend to be not correlated with variations in the horizontal wind speed and in the temperature. In this sense, low-frequency processes acting in the surface layer tend to cause the correlation coefficients $r_{w t}$ and $r_{u w}$ to decrease. 
In figure 2 open symbols represent all the data with $r_{w t}>0.3$ and a more restricted criterion of only data with $r_{w t}>0.5$ is represented by closed symbols. It is clear that a much larger scatter results from data with relatively low $r_{w t}$, which largely reduces the applicability of methods based on local similarity relationships.

\section{Modulation of turbulence in the surface layer}

The analysis from previous section highlights that MOS theory performs reasonably well only for data where the correlation $r_{w t}$ is higher than 0.5. As shown, there are indications that the deviations of $r_{w t}$ from the textbook 0.5 value are characterized by the presence of motions of (low-frequency) large eddies. To further analyze this modulation, we investigate the relation between the parameter $v^{*}$ ("fluctuating" friction velocity), introduced by McNaughton (2006), with the friction velocity $u^{*}$. We recall that $v^{*}$ is a parameter that represents the additional energy transported down from the variable motions of the outer layer to the surface layer (McNaughton, 2006) and can be estimated from measurements of $\varepsilon$ and $u^{*}$.

In Figure 3 a relationship between the correlation coefficient $r_{u w}$ and the ratio $v^{*} / u^{*}$ is shown. It is observed that when $v^{*}$ is on the order of two times $u^{*}$ or higher $\left(v^{*} / u^{*} \geq 2\right)$ the correlation $r_{u w}$ is clearly lower than the usually observed value of (-)0.35 in the surface layer over flat uniform terrain (Kaimal and Finnigan, 1994). Note that $r_{u w}$ is negative and we are presenting it as positive values here. This supports the interpretation discussed previously: as lowfrequency motions influence the structure of the surface layer eddies, they induce deviations from the 'classic' surface layer over Amazonian forest.

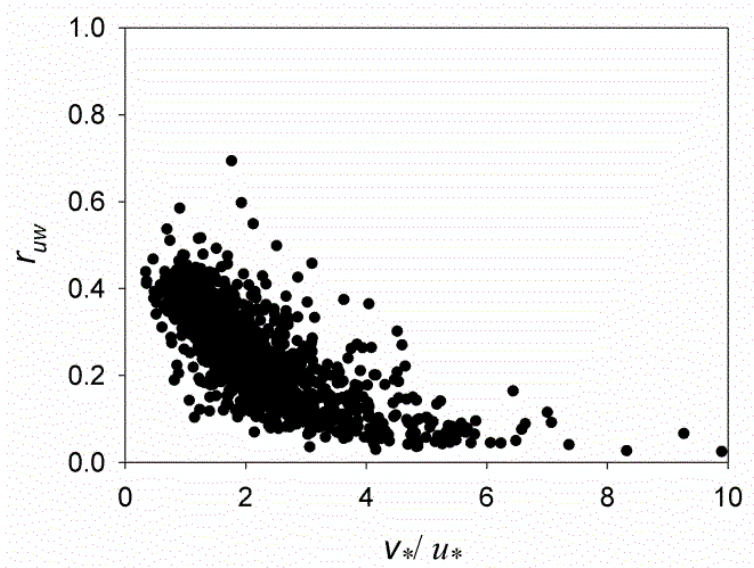

Figure 3: Relation between the correlation coefficient $r_{u w}$ (absolute values) and the ratio $v^{*} / u^{*}$, measured over Amazonian forest at the ZF2 forest site.

Based on these results, we propose that the relation between the two velocity scales could be used as an indicator of the strength of low frequency modulations in the region: when the ratio $v^{*} / u^{*}$ is above the threshold of $\sim 2$, it is likely that the influence of low-frequency motions in the surface layer is high, and in these cases the surface layer is different from the textbook descriptions.

In Figure 4 we present the histogram of the ratio $v^{*} / u^{*}$ for the measurements at the K34 site (unstable conditions only). It is observed that $v^{*} / u^{*}$ is higher 2 for roughly $50 \%$ of the time. During these cases we expect MOS theory to be invalid, with clear implications to any estimate from indirect methods or models of flux exchange that rely on this theory.

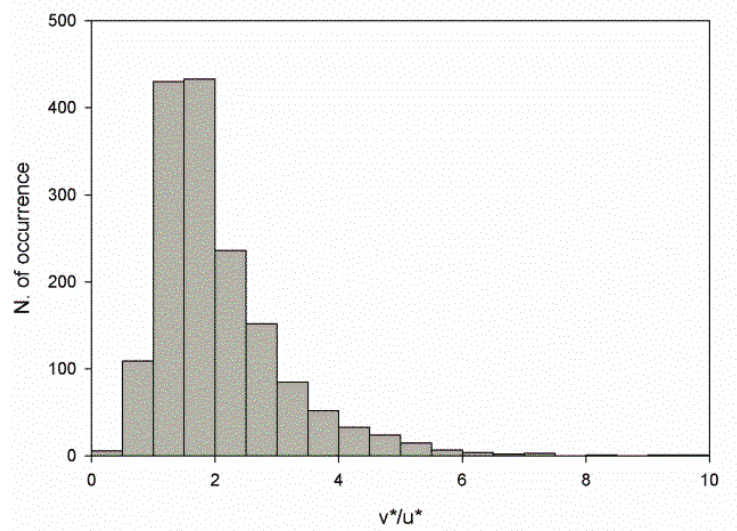

Figure 4: Histogram of measurements of ratio $v^{*} / u^{*}$ obtained in unstable conditions only at the ZF2 forest site. 


\section{Conclusions}

To investigate the influence of lowfrequency variations in the surface layer over Amazonia forest, we studied how turbulence statistics depend on time scales and spatial scales and estimate the 'outer layer' 'fluctuating' friction velocity $\left(v^{*}\right)$ as proposed by McNaughton (2006) to represent the additional energy transported down from the variable motions of the outer layer to the surface layer.

We found that the MOS similarity relationships provide reasonable results only when there is little influence of low frequency variations in the turbulent processes, an effect that may be empirically assessed by estimating the ratio between $v^{*}$ and $u^{*}$. When $v^{*}$ is about 2 times $u^{*}$ or higher, the structure of turbulence in the surface layer is different from the textbook descriptions. Our measurements in the ZF-2 forest site indicate that this happens during about $50 \%$ of the time in unstable conditions.

\section{References}

Finnigan, J.J., Clement, R., Malhi, Y., Leuning, R., Cleugh, H.A., 2003. A re-evaluation of long-term flux measurement techniques. Part I. Averaging and coordinate rotation. Boundary-Layer Meteorol. 107, 1-48.

Hogstrom, U., 1990. Analysis of turbulence structure in the surface-layer with a modified similarity formulation for near neutral conditions. J. Atmos. Sci. 47, 1949-1972.

Howell, J. F., Mahrt, L., 1997. Multiresolution lux decomposition. Boundary-Layer Meteorol. 83, 117-137.

Kaimal, J.C., Finnigan, J.J., 1994. Atmospheric Boundary Layer Flows: Their Structure and Measurement. Oxford University Press, New York, 289 pp.

Malhi, Y., McNaughton, K.G., von Randow, C., 2004. Low frequency atmospheric transport and surface flux measurements. In: Lee, X., Massman, W., Law, B. (Eds.), Handbook of Micrometeorology: A Guide for Surface Flux Measurement and Ana- lysis. Kluwer Academic Publishers, Dordrecht, The Netherlands, pp. 101118.

McNaughton, K.G., 2004. Turbulence structure of the unstable atmo- spheric surface layer and transition to the outer layer. Boundary- Layer Meteorol. 112, 199-221.

McNaughton, K.G., 2006. On the kinetic energy budget of the unstable atmospheric surface layer. Boundary-Layer Meteorol. 118, 83-107.

Stull, R. B. 1988. An Introduction to Boundary Layer Meteorology. Kluwer Academic Publishers, Dordrecht, The Netherlands, 670 pp.

Twine, T.E., Kustas, W.P., Norman, J.M., Cook, D.R., Houser, P.R., Meyers, T.P., Prueger, J.H., Starks, P.J., Wesely, M.L., 2000. Correcting eddycovariance flux underestimates over a grassland. Agric. For. Meteorol. 103, 279-300.

Von Randow, C., Sa, L.D.A., Gannabathula, P., Manzi, A.O., Arlino, P.R.A., Kruijt, B., 2002. Scale variability of atmospheric surface layer fluxes of energy and carbon over a tropical rain forest in southwest Amazonia. 1. Diurnal conditions. J. Geophys. Res. 107 (0), 8062, doi:10.1029/2001JD000379.

Von Randow, C., Manzi, A.O., Kruijt, B., Oliveira, P.J., Zanchi, F.B., Silva, R.L., Hodnett, M.G., Gash, J.H.C., Elbers, J.A., Waterloo, M.J., Cardoso, F.L., Kabat, P., 2004. Comparative measurements and seasonal variations in energy and carbon exchange over forest and pasture in South West Amazonia. Theor. Appl. Climatol. 78, 5-26.

Von Randow, C., Kruijt, B., Holtslag, A.A.M., 2006. Low-frequency modulation of the atmospheric surface layer over Amazonian rain forest and its implication for similarity relationships. Agric. For. Meteorol. 141, 192-207. 